\title{
Editorial
}

\section{Virtual Reality and Games}

\author{
Carolina Cruz-Neira ${ }^{1}$, Marcos Fernández ${ }^{2}$ and Cristina Portalés ${ }^{2, *}$ (1) \\ 1 Emerging Analytics Center, University of Arkansas at Little Rock, 2801 South University Ave, Little Rock, \\ AR 72204, USA; cxcruz@ualr.edu \\ 2 Institute of Robotics and Information and Communication Technologies (IRTIC), Universitat de València, \\ 46980 València, Spain; marcos.fernandez@uv.es \\ * Correspondence: cristina.portales@uv.es; Tel.: +34-963-543-557
}

Received: 20 February 2018; Accepted: 21 February 2018; Published: 26 February 2018

\section{Introduction}

The concept of Virtual Reality (VR) dates back to around 1930, where different technologies and concepts arise. For instance, in 1929 Edward Link created the Link Trainer (further patented in 1931), reported to be the first example of a commercial flight simulator, being entirely electromechanical. Also, in the 1930s, the visionary, science fiction writer Stanley G. Weinbaum brings a story (Pygmalion's Spectacles) that introduces the early idea of a pair of goggles that makes the wearer experience a fictional world through holograms, smell, taste, and touch. Weinbaum describes uncanny experiences for those wearing the goggles, aligned with the modern experiences of VR. It is in the mid 1950s when cinematographer Morton Heilig developed the Sensorama (further patented in 1962), which resembled a kind of an arcade-style theatre cabinet. The technology integrated in the Sensorama allowed an individual seeing stereoscopic films enhanced with seat motion, vibration, stereo sound, wind, and aromas, which were triggered during the films [1], intending to fully immerse the individual in the film. Since then, many authors have used VR as platforms that support a variety of fields, such as training and learning [2-5], entertainment [6-8], flight and driving simulation [9-11], cultural heritage [12-14], and scientific and medical visualizations [15-17], to cite some.

Overall, VR can be referred as a technology that allows for replacing the real world by a synthetic one, making the user believe that she/he is in another realm [18]. It involves a set of technologies that are used to create computer-generated virtual environments where users can experience and interact just as if they would do in real life [19]. To that end, it integrates stereoscopic displays, motion tracking hardware, input devices, and software platforms [20].

The characteristics of VR make it a relevant technology for gaming purposes. The entertainment industry and research is full of examples involving VR applications [6,21]. Gaming in VR is, however, not only restricted to entertainment, but it has been expanded to different fields, mainly with the purpose to learn or train through gaming, usually referred as edutainment or serious games. Some examples can be found in [22-25].

Simulation techniques are used to build virtual worlds in which users are immersed and to deceive the human senses, so that the perceptual cues that reach the brain are aligned with an alternative reality. These perceptual cues can be of different nature, including acoustic, visual, haptic, smell, and motion stimuli. VR is a consolidated solution in many cases (e.g., driving simulators) as it provides: safety and risk reduction; costs reduction; greater trial availability; no damage; possibility of recreating a variety of situations; and, the possibility of repeating the same situations under the same conditions [18].

VR is a multimodal, interactive technology, since users need to interact with the simulated world as naturally as possible, and do it in a similar way as they would do it the real world. This is quite complex, and therefore in some VR applications interaction is restricted to a certain extent or involving only one or two senses (e.g., visual and sonic stimuli). In fact, due to current technological barriers and/or cost issues, many VR applications are not fully immersive, do not use natural interfaces, and, 
therefore, do not provide a seamless/credible alternative reality. Therefore, there is a need to provide improved and cost efficient solutions.

\section{Purpose of This Special Issue}

Recent developments in motion sensors, graphics, multimodal display technologies, and interaction have paved the way for expanding the Virtual Reality (VR) gaming possibilities beyond traditional entertainment, providing seamless immersive experiences in highly interactive synthetic worlds. From active adventures to relaxing, passive immersion, VR evolves beyond the related technologies to take the user(s) into the heart of the story itself, perceiving it as in first person. The magic of VR makes serious games such as those involving education and training an engaging adventure, providing learning skills to improve users' expertise. Industries related to real state, automobile, advertising, or tourism are currently using VR gaming as a claim to attract new audiences or involve clients in new engaging experiences. As well, media artists, filmmakers, musicians, and designers find in VR gaming an inspiring resource for their creations.

From a research point of view, there are many aspects that should be addressed. For instance, considering the variety of new sensors and displays technologies dealing with different kind of stimuli, issues regarding the level of immersion may arise. Also, what could be the optimal combination of these technologies depending on the kind of simulated VR and the proposed games? User-related studies, such as the level of engagement, satisfaction, learning or skills improvement needs also to be investigated.

This Special Issue aimed to provide a collection of high quality research articles that address broad challenges in both theoretical and applied aspects of VR and games, including new software and hardware developments and user-related studies. We also aimed to assess old questions in the new VR-gaming realm.

\section{Summary of Papers Published in This Special Issue}

This special issue details results from a total of seven papers (four original papers and three review papers) that unpack the relevance of Virtual Reality and Games. In the following lines, an outline is given on these papers, highlighting their main findings, followed by a discussion. The readers are addressed to read the full papers in order to retrieve more information.

The paper entitled "A Survey on the Procedural Generation of Virtual Worlds" [26] brings a survey on different algorithms for the automatic generation of content for virtual worlds, focusing in games. The authors focus on the term procedural content generation (PCG) and then introduce in detail the algorithms to generate realistic objects: landscapes and vegetation, road networks, buildings, living beings (humans and creatures) and stories. All of the reported classes of procedurally creatable objects are exemplified with detailed images. A further discussion is provided, where they emphasize a good compromise between the realism of the objects and the performance of the algorithms. The survey also assesses each generated object type in terms of its applicability in games and simulations of virtual worlds. They conclude the work providing a table that collects the most important contributions to the field of PCG in research and in practice, and ranking their presence from very high to very low.

In the paper, "Exploration of the 3D World on the Internet Using Commodity Virtual Reality Devices" [27], the technical basics and applications of graphically interactive and online VR frameworks are discussed. The paper brings a system that automatically extracts and displays left and right stereo images from diverse Internet search engines. In this way, aligned left and right stereo photos derived from three-dimensional (3D) contents are returned to the users, which are viewable through VR glasses. Additionally, to reduce possible copyright issues, only the search for images that are "labeled for reuse" is performed, so the returned pictures can be used for any purpose. The system specifies if the picture is a side-by-side stereo pair, an anaglyph, a stereogram, or just a two-dimensional (2D) image. Then, it generates a stereo pair from the collected dataset, to seamlessly display 3D visualizations on a variety of VR devices. From some initial experiment results, the system is reported to be relatively fast, 
accurate, and easy to implement. The authors claim that, with such a system, Internet users all over the World could easily visualize millions of real life stereo datasets that are publicly available, which are believed to be useful for VR testing and learning purposes.

In the paper "On the Design of Virtual Reality Learning Environments in Engineering" [28] the authors highlight the relevance of VR in engineering. They bring out that the engineering applications based on VR cover approximately one half of the total number of VR resources. They discuss the capabilities of different computational software for designing VR applications in engineering education and propose a general flowchart as a guide for designing VR resources which overall involves: determining the VR usefulness, the technical design of the VR application and the development and evaluation of the VR application. The authors also claim that the obtained results can be easily extrapolated to other knowledge areas without any loss of generality. Therefore, the research shown in this paper can serve as a guide for creating VR applications of any kind.

In the paper "On a First Evaluation of ROMOT-A RObotic 3D MOvie Theatre-For Driving Safety Awareness" [18] authors introduce the ROMOT system and present a case study related to driving safety that includes some user tests. Technologically, the system consists on a robotic motion platform with multimodal devices and supports audience-film interaction. The system is also versatile, as it supports different setups and kind of contents: a first-person movie, a mixed reality environment, a virtual reality interactive environment and an augmented reality mirror-based scene [29]. The test performed with a set of users give satisfactory scores for the system usability and the individual's satisfaction. The authors claim that, although there are some commercial solutions that are referred as four-dimensional (4D) or five-dimensional (5D) cinemas, there is a lack of research works dealing with the construction and audience evaluation of such systems.

The review given in the paper entitled "Supporting Optimal Aging through the Innovative Use of Virtual Reality Technology" [30] explores the relevance of using VR for older adults. The authors bring out that, although VR has been used to address the health issues of older adults, its applicability to social connectedness is still underrepresented in the literature, also lacking knowledge about its efficacy in contributing to overall wellness and well being for this population. Authors explore some virtual and augmented reality tools that have been employed in the elder health care field and to facilitate optimal wellness in aging. They claim that such technological advances have the potential to significantly impact one of the most important issues that older people face: social isolation and loneliness.

The review paper "Immersive Environments and Virtual Reality: Systematic Review and Advances in Communication, Interaction and Simulation" [31] highlight the relevance of the research lines of VR and immersive environments, which can be applied to numerous scientific and educational domains. The authors claim that immersive digital media need new approaches regarding their interactive and immersive features, which involves the design of new narratives and relationships with users. They also report the need to design and conceive new forms of representing information and improving users' interaction with immersive environments. This review focuses on the cutting-edge expressive, interactive and representative potential of immersive digital technologies. It also considers future possibilities regarding the evolution of these technologies in coming years in order to apply them to diverse scientific, artistic, or informational and educational domains. Authors report that VR is not only an ensemble of technological innovations, but also a concept, and propose models in other domains, such as UX (user experience) or interaction design. They claim that this concept can help researchers and developers to design new experiences and conceive new expressive models that can be applied to a wide range of scientific lines of research and educational dynamics.

Finally, the review paper "Augmented Reality Video Games: New Possibilities and Implications for Children and Adolescents" [32] focuses on the relevance of augmented reality (AR) video games, examining both the benefits and dangers of this technology for children and adolescents. Authors report that in the last years, the video game market has embraced this technology, a class of video games that is set to grow as gaming technologies develop. They claim that, given the widespread use 
of video games among children and adolescents, the health implications of AR technology must be closely examined, as the full immersion and physical movement required in AR video games may also put users at risk for physical and mental harm.

In summary, this Special Issue explored the role of VR in gaming. The reported works involve research on both software and hardware technologies, from off the shelf to commercial solutions, from small devices to huge machines, also expanding the technology to AR applications and including different audiences. The potential of VR gaming for learning, driving, wellbeing, and entertainment have been explored, among others. We can say that the main aim of this special issue has been covered, as the papers are a reflection of the current research trends in VR and games.

Acknowledgments: The authors thank the various contributors, reviewers and journal staff at Multimodal Technologies and Interaction for making this Special Issue a success.

Author Contributions: All authors have contributed equally.

Conflicts of Interest: The authors declare no conflict of interest.

\section{References}

1. Heilig, M.L. Sensorama Simulator. US3050870A. 28 August 1962.

2. Gimeno, J.; Fernández, M.; Morillo, P.; Coma, I.; Pérez, M. A reconfigurable immersive workbench and wall-system for designing and training in 3D environments. In Proceedings of the International Conference on Virtual, Augmented and Mixed Reality, Beijing, China, 22-27 July 2007.

3. Pan, Z.; Cheok, A.D.; Yang, H.; Zhu, J.; Shi, J. Virtual reality and mixed reality for virtual learning environments. Comput. Graph. 2006, 30, 20-28. [CrossRef]

4. Gavish, N.; Gutiérrez, T.; Webel, S.; Rodríguez, J.; Peveri, M.; Bockholt, U.; Tecchia, F. Evaluating virtual reality and augmented reality training for industrial maintenance and assembly tasks. Interact. Learn. Environ. 2015, 23, 778-798. [CrossRef]

5. Lau, K.W.; Lee, P.Y. The use of virtual reality for creating unusual environmental stimulation to motivate students to explore creative ideas. Interact. Learn. Environ. 2015, 23, 3-18. [CrossRef]

6. Vargas González, A.N.; Kapalo, K.; Koh, S.; LaViola, J. Exploring the virtuality continuum for complex rule-set education in the context of soccer rule comprehension. Multimodal Technol. Interact. 2017, 1, 30. [CrossRef]

7. Hock, P.; Benedikter, S.; Gugenheimer, J.; Rukzio, E. Carvr: Enabling in-car virtual reality entertainment. In Proceedings of the 2017 CHI Conference on Human Factors in Computing Systems, Denver, CO, USA, 6-11 May 2017; pp. 4034-4044.

8. Bates, J. Virtual reality, art, and entertainment. Presence 1992, 1, 133-138. [CrossRef]

9. Casas, S.; Coma, I.; Portalés, C.; Fernández, M. Towards a simulation-based tuning of motion cueing algorithms. Simul. Model. Pract. Theory 2016, 67, 137-154. [CrossRef]

10. Tudor, S.; Carey, S.; Dubey, R. Development and evaluation of a dynamic virtual reality driving simulator. In Proceedings of the 8th ACM International Conference on PErvasive Technologies Related to Assistive Environments, Corfu, Greece, 1-3 July 2015.

11. Cox, D.J.; Davis, M.; Singh, H.; Barbour, B.; Nidiffer, F.D.; Trudel, T.; Mourant, R.; Moncrief, R. Driving rehabilitation for military personnel recovering from traumatic brain injury using virtual reality driving simulation: A feasibility study. Mil. Med. 2010, 175, 411-416. [CrossRef] [PubMed]

12. Portalés, C.; Alonso-Monasterio, P.; Viñals, M.J. 3D virtual reconstruction and visualisation of the archaeological site Castellet de Bernabé (Llíria, Spain). Virtual Archaeol. Rev. 2017, 8, 72-85. [CrossRef]

13. Richards-Rissetto, H.; Robertsson, J.; von Schwerin, J.; Agugiaro, G.; Remondino, F.; Girardi, G. Geospatial virtual heritage: A gesture-based 3D gis to engage the public with ancient maya archaeology. Archaeol. Digit. Era 2014, 6, 118-130.

14. Gaitatzes, A.; Christopoulos, D.; Roussou, M. Reviving the past: Cultural heritage meets virtual reality. In Proceedings of the 2001 Conference on Virtual Reality, Archeology, and Cultural Heritage, Glyfada, Greece, 28-30 November 2001; pp. 103-110. 
15. Cruz-Neira, C.; Leigh, J.; Papka, M.; Barnes, C.; Cohen, S.M.; Das, S.; Engelmann, R.; Hudson, R.; Roy, T.; Siegel, L. Scientists in wonderland: A report on visualization applications in the cave virtual reality environment. In Proceedings of the IEEE 1993 Symposium on Research Frontiers in Virtual Reality, San Jose, CA, USA, 23-26 October 1993; pp. 59-66.

16. Moro, C.; Stromberga, Z.; Stirling, A. Virtualisation devices for student learning: Comparison between desktop-based (Oculus Rift) and mobile-based (Gear Vr) virtual reality in medical and health science education. Australas. J. Educ. Technol. 2017, 33. [CrossRef]

17. Chirico, A.; Lucidi, F.; De Laurentiis, M.; Milanese, C.; Napoli, A.; Giordano, A. Virtual reality in health system: Beyond entertainment. A mini-review on the efficacy of Vr during cancer treatment. J. Cell. Physiol. 2016, 231, 275-287. [CrossRef] [PubMed]

18. Casas, S.; Portalés, C.; García-Pereira, I.; Fernández, M. On a first evaluation of romot-A robotic 3D movie theatre-For driving safety awareness. Multimodal Technol. Interact. 2017, 1, 6. [CrossRef]

19. Emspak, J. What Is Virtual Reality? Available online: https:/ / www.livescience.com/54116-virtual-reality. htm (accessed on 11 January 2018).

20. Parisi, T. Learning Virtual Reality: Developing Immersive Experiences and Applications for Desktop, Web, and Mobile; O'Reilly Media, Inc.: Sebastopol, CA, USA, 2015.

21. Díaz, D.; Boj, C.; Portalés, C. Hybridplay: A new technology to foster outdoors physical activity, verbal communication and teamwork. Sensors 2016, 16, 586. [CrossRef] [PubMed]

22. Gamito, P.; Oliveira, J.; Coelho, C.; Morais, D.; Lopes, P.; Pacheco, J.; Brito, R.; Soares, F.; Santos, N.; Barata, A.F. Cognitive training on stroke patients via virtual reality-based serious games. Disabil. Rehabilit. 2017, 39, 385-388. [CrossRef] [PubMed]

23. Burke, J.W.; McNeill, M.; Charles, D.K.; Morrow, P.J.; Crosbie, J.H.; McDonough, S.M. Optimising engagement for stroke rehabilitation using serious games. Vis. Comput. 2009, 25, 1085. [CrossRef]

24. Mortara, M.; Catalano, C.E.; Bellotti, F.; Fiucci, G.; Houry-Panchetti, M.; Petridis, P. Learning cultural heritage by serious games. J. Cult. Heritage 2014, 15, 318-325. [CrossRef]

25. Stone, R. Serious games: Virtual reality's second coming? Virtual Real. 2009, 13, 1-2. [CrossRef]

26. Freiknecht, J.; Effelsberg, W. A survey on the procedural generation of virtual worlds. Multimodal Technol. Interact. 2017, 1, 27. [CrossRef]

27. Nguyen, M.; Tran, H.; Le, H. Exploration of the 3D world on the internet using commodity virtual reality devices. Multimodal Technol. Interact. 2017, 1, 15. [CrossRef]

28. Vergara, D.; Rubio, M.; Lorenzo, M. On the design of virtual reality learning environments in engineering. Multimodal Technol. Interact. 2017, 1, 11. [CrossRef]

29. Giner Martínez, F.; Portalés Ricart, C. The augmented user: A wearable augmented reality interface. In Proceedings of the International Conference on Virtual Systems and Multimedia (VSMM'05), Ghent, Belgium, 3-7 October 2005; Hal Thwaites: Ghent, Belgium; pp. 417-426.

30. Hughes, S.; Warren-Norton, K.; Spadafora, P.; Tsotsos, L. Supporting optimal aging through the innovative use of virtual reality technology. Multimodal Technol. Interact. 2017, 1, 23. [CrossRef]

31. Rubio-Tamayo, J.; Gertrudix Barrio, M.; García García, F. Immersive environments and virtual reality: Systematic review and advances in communication, interaction and simulation. Multimodal Technol. Interact. 2017, 1, 21. [CrossRef]

32. Das, P.; Zhu, M.O.; McLaughlin, L.; Bilgrami, Z.; Milanaik, R. Augmented reality video games: New possibilities and implications for children and adolescents. Multimodal Technol. Interact. 2017, 1, 8.

(C) 2018 by the authors. Licensee MDPI, Basel, Switzerland. This article is an open access article distributed under the terms and conditions of the Creative Commons Attribution (CC BY) license (http://creativecommons.org/licenses/by/4.0/). 